University of Nebraska - Lincoln

DigitalCommons@University of Nebraska - Lincoln

Faculty Publications, Department of Child, Youth, and Family Studies

Child, Youth, and Family Studies, Department of

$4-22-2021$

\title{
Cultural Bereavement and Resilience in Refugee Resettlement: A Photovoice Study With Yazidi Women in the Midwest United States
}

\author{
Julie A. Tippens \\ University of Nebraska-Lincoln, jtippens@unl.edu \\ Kaitlin Roselius \\ University of Nebraska-Lincoln, kaitlin.roselius@gmail.com \\ Irene Padasas \\ University of Nebraska-Lincoln \\ Gulie Khalaf \\ Yezidis International, Lincoln, Nebraska \\ Kara Kohel \\ University of Nebraska-Lincoln, kara.kohel@unl.edu \\ Follow this and additional works at: https://digitalcommons.unl.edu/famconfacpub \\ See next page for additional authors \\ Part of the Developmental Psychology Commons, Family, Life Course, and Society Commons, Other \\ Psychology Commons, and the Other Sociology Commons
}

Tippens, Julie A.; Roselius, Kaitlin; Padasas, Irene; Khalaf, Gulie; Kohel, Kara; Mollard, Elizabeth; and Sheikh, Izdihar (Vianne), "Cultural Bereavement and Resilience in Refugee Resettlement: A Photovoice Study With Yazidi Women in the Midwest United States" (2021). Faculty Publications, Department of Child, Youth, and Family Studies. 302.

https://digitalcommons.unl.edu/famconfacpub/302

This Article is brought to you for free and open access by the Child, Youth, and Family Studies, Department of at DigitalCommons@University of Nebraska - Lincoln. It has been accepted for inclusion in Faculty Publications, Department of Child, Youth, and Family Studies by an authorized administrator of DigitalCommons@University of Nebraska - Lincoln. 


\section{Authors}

Julie A. Tippens, Kaitlin Roselius, Irene Padasas, Gulie Khalaf, Kara Kohel, Elizabeth Mollard, and Izdihar (Vianne) Sheikh 


\title{
Cultural Bereavement and Resilience in Refugee Resettlement: A Photovoice Study With Yazidi Women in the Midwest United States
}

\author{
Julie A. Tippens, ${ }^{1}$ Kaitlin Roselius, ${ }^{1}$ Irene Padasas, ${ }^{1}$ \\ Gulie Khalaf, ${ }^{2}$ Kara Kohel, ${ }^{1}$ Elizabeth Mollard, ${ }^{3}$ \\ and Izdihar (Vianne) Sheikh ${ }^{1}$
}

1 University of Nebraska-Lincoln, Lincoln, Nebraska, USA 2 Yezidis International, Lincoln, Nebraska, USA

3 University of Nebraska Medical Center, Lincoln, Nebraska, USA

Corresponding author - Julie A. Tippens, Assistant Professor, Department of Child, Youth and Family Studies, University of Nebraska-Lincoln, 205 Louise Pound Hall, Lincoln, NE 68588, USA. Email: jtippens@unl.edu

ORCID Julie A. Tippens https://orcid.org/0000-0003-0465-3570

\begin{abstract}
This study explored how ethnic Yazidi refugee women overcome adversity to promote psychosocial health and well-being within the context of U.S. resettlement. Nine Yazidi women participated in two small photovoice groups, each group lasting eight sessions (16 sessions total). Women discussed premigration and resettlement challenges, cultural strengths and resources, and strategies to overcome adversity. Yazidi women identified trauma and perceived loss of culture as primary stressors. Participants' resilience processes included using naan (as sustenance and symbol)
\end{abstract}

Published in Qualitative Health Research (2021), DOI: 10.1177/10497323211003059, 18 pp. Copyright (C) 2021 Julie A. Tippens, Kaitlin Roselius, Irene Padasas, Gulie Khalaf, Kara Kohel, Elizabeth Mollard, and Izdihar (Vianne) Sheikh. Published by SAGE Publications. Used by permission.

Published April 22, 2021. 
to survive and thrive as well as by preserving an ethnoreligious identity. Findings suggest that women's health priorities and resilience-promoting strategies center on fostering a collective cultural, religious, and ethnic identity postmigration. Importantly, women used naan (bread) as a metaphor to index cultural values, experiences of distress, and coping strategies. We discuss implications for this in promoting refugees' mental and psychosocial health in U.S. resettlement.

Keywords: refugees, psychosocial health, mental health, trauma, qualitative, photovoice, visual methods, Iraq, United States

The associations between forced migration and poor mental and psychosocial health are well documented. Stressors associated with premigration, flight, and postmigration, including exposure to violence, fragmented family and social networks, and loss of identity or status, have generally deleterious effects on refugees' psychosocial health (Siriwardhana et al., 2014; Turrini et al., 2017). In premigration contexts, women are vulnerable to human rights abuses such as sexual exploitation or the use of rape and sexual torture as wartime weapons (Rai \& Paul, 2020; Shishehgar et al., 2017), which can have longlasting effects on physical, mental, and social well-being. Dangerous transit risks include potential for being trafficked and vulnerability to violence from smugglers or traffickers (Rai \& Paul, 2020). Postmigration factors such as racism, discrimination, and xenophobia have been associated with decreased social support, loss of hope, and poor mental health (Hynie, 2018; Szaflarski \& Bauldry, 2019; Ziersch et al., 2020). Women have been shown to be at higher risk for poor mental health outcomes compared with male counterparts in postmigration resettlement (Shishehgar et al., 2017). In an integrative review of 20 articles on refugee women's sociocultural experiences and health, Shishehgar and colleagues (2017) identified multiple factors that diminished psychosocial well-being, such as lack of proficiency in host country language and fear of being misunderstood by available interpreters, challenges navigating new sociocultural landscapes, diminished spousal and familial support, and fragmented social networks and isolation.

Despite threats to well-being, many refugees overcome adversity to demonstrate positive psychosocial health and well-being (Posselt et al., 2019; Siriwardhana et al., 2014). Strengthening resilience has been identified as an important strategy to improve refugees' emotional 
well-being, including in U.S. resettlement (U.S. Office of Refugee Resettlement [ORR], 2019). This is reflective of a larger paradigm shift that, while acknowledging the cumulative impact of trauma and adversity on health and well-being, seeks to understand how refugees overcome hardship as well as leverage these individual and collective resources to promote well-being and integration. To explore this larger phenomenon in a resettlement setting, we conducted a photovoice study with ethnoreligious Yazidi women $(N=9)$. The purpose of our study was twofold: (a) to identify women's health and well-being priorities to inform community services, and (b) to explore the social, cultural, and structural determinants of Yazidi women's resilience.

\section{Yazidis and Yazidism: Centuries of Persecution and Genocide}

Yazidis (also Yezidis, Ezidi, or Daasin) are an endogamous monotheistic religious group indigenous to northern Iraq, northeastern Syria, southeastern Turkey, and the Caucasus region (De Vido, 2018; Hafiz, 2014). The total global population of Yazidis is approximately 1 million (Doucet, 2018). Most Yazidis now reside in the Kurdistan region of northern Iraq (Eller, 2019; Yazda, 2020). Yazidism is an ancient religion that predates Judaism, Islam, and Christianity (Yezidis International, n.d.). The dogma of the faith centers in seven angels to whom God entrusted the affairs of the world; Malik Tāwūs (also Tawuse Melek ), or the Peacock Angel, is the highest among them (Allison, 2017). The holiest temple or shrine, Lalish, is located in the Dohuk province of Iraqi Kurdistan; Yazidis who are able are expected to make a pilgrimage to visit Lalish at least once in their lives (Kizilhan, 2017; Kurt, 2016). Many followers of other monotheistic religions in the region equated the Peacock Angel as an unredeemed spirit, and its believers as "devil worshippers," resulting in centuries of persecution against Yazidis. Unofficial documents dating to the Ottoman Empire reveal depictions of Yazidis as "pervert communities," "looters," and "bandits who do not pay taxes" (Basci, 2016). Yazidis were subjected to assimilation for centuries; those who refused were massacred as early as the Ottoman Empire (Basci, 2016).

Continued persecution into the 21st century, first under Saddam Hussein and later by the rise of sectarian violence in Iraq after 
Hussein's death, resulted in widespread displacement (Al-Khalidi et al., 2007; Hanish, 2009). The Yazidis have endured at least 72 genocides over the past 800 years (Isakhan \& Shahab, 2020). The most recent genocide began in August 2014 when the Islamic State of Iraq and the Levant (ISIL) massacred more than 7,000 Yazidis in the Sinjar region (Kizilhan \& Noll-Hussong, 2017). About 50,00o Yazidis, particularly women and children, fled into the mountainous region of Sinjar for refuge and were trapped without food, water, or shelter (Cooper \& Shear, 2014; "UN Security Council Condemns Attacks by Iraqi Jihadists," 2014). Those unable to escape were killed or kidnapped. Women and girls were abducted, enslaved, raped, murdered, and sold as sex slaves in Arab markets (Kizilhan \& Noll-Hussong, 2017).

The ISIL genocide has had an unsurprisingly deleterious effect on Yazidi refugees' mental health. Grossman et al. (2019) reported higher than 50\% prevalence of complex post-traumatic stress disorder (CPTSD) among Yazidi women $(N=108)$ who were former ISIL captives. Nasiroğlu and Ceri (2016) found high rates of post-traumatic stress disorder (PTSD; 36.4\%) and depression (32.7\%) among Yazidi children and adolescents $(N=55)$; witnessing death or violence were risk factors for both traumatic stress and depression. Female refugees in this study expressed more concern and worry about those left behind compared with their male counterparts (Nasıroğlu \& Ceri, 2016). The 2014 genocide also triggered PTSD among Yazidi refugees who were not physically present and had been living outside of the region: in a sample of 512 (61.9\% female) Yazidi refugees residing in Germany, more than a quarter surveyed fulfilled PTSD criteria (Tagay et al., 2017). Women were more likely than men to endorse PTSD symptoms (31.5\% vs. 16.4\%, $p<.0001$; Tagay et al., 2017). The effects of genocide on the Yazidi diaspora should not be underestimated.

\section{Theoretical Frameworks: Cultural Bereavement and Resilience}

\section{Cultural Bereavement}

Trauma experienced by refugees in premigration, flight, and postmigration (e.g., first asylum camps and cities) may persist well into resettlement and is often categorized in terms of mental health risks 
and outcomes, such as anxiety, depression, and PTSD. Caution should be exercised, however, applying western-centric categories in crosscultural interventions as diagnoses may not account for culturally meaningful patterns of grief, help-seeking, or communicating distress (Baarnhielm et al., 2017; Nichter, 1981; Raasch, 2019). Indeed, there is potential for long-term harm from "untested, ineffective, and culturally insensitive" global mental health care frameworks (Raasch, 2019, p. 2). To provide greater context for refugees' suffering and poor mental health outcomes, Eisenbruch (1991) employed the framing of "cultural bereavement," distress that encompasses the trauma of loss of homeland, identity, and social connectedness in tandem with the psychological traumas related to forced migration (e.g., experiencing or witnessing violence) and relocation. As a holistic way to conceptualize distress, cultural bereavement recognizes “... the total experience of the uprooted person-or group-resulting from loss of old social structures, cultural values and meanings, and self" (Eisenbruch, 1991, p. 674). Cultural bereavement is associated with the constant intrusion of past images, visits by "supernatural forces" from the past in waking and dream states, and complex feelings of guilt, anger, and despair over abandoning one's homeland, culture, and people (Eisenbruch, 1991, 1997).

Cultural bereavement conceptually encompasses the "liminal" or "betwixt and between" status of refugees in postmigration settings (Harrell-Bond \& Voutira, 1992; Turner, 1969; in Harrell-Bond \& Voutira, 1992). However, Eisenbruch's framework does not explicitly consider how exposure to human rights violations, trauma, and discrimination influence group identity formation as a central component of cultural bereavement concerning belongingness (see Kevers et al., 2017). Refugees who have been resettled to a third country have diminishing access to their cultural traditions and contend with myriad losses, including familiar languages, values, places, supportive networks, and memories (Eisenbruch, 1991; Wachter et al., 2020). In addition, Kirmayer et al., (2014b) remind us that factors such as race, ethnicity, religion, and culture advantage or marginalize individuals and groups in different contexts and are, therefore, powerful determinants of health. Indeed, new societies' attitudes toward cultural, racial, and religious differences may affect newcomer refugees' differential experiences of structural and interpersonal racism, ageism, 
and xenophobia (Bhugra et al., 2011). Resultantly, refugees may experience hatred in tandem with lack of access to safe housing, employment, and other opportunities to integrate into the host culture (Bhugra et al., 2011). A critical aspect of cultural bereavement, then, is how structural insecurity and discrimination may influence reactive identity mobilization, a (in part emotional) process of diasporic identity formulation (Kinnvall, 2004), as refugees seek ontological security in new host societies.

\section{Resilience}

Resilience offers a theoretical positionality that draws attention to the creativity, imagination, and fortitude needed to overcome adversity to survive and even thrive. Ungar's (2011) conceptualization of resilience as a quality of social and physical ecologies shifted from earlier foci of resilience as trait-based. Four principles guide this social ecological perspective of resilience. The first is decentrality or moving beyond individual-level examinations of resilience to process-oriented analyses of environments and ecologies. Second, complexity considers the dynamism of contextual and temporal factors that foster resilience. To this point, Ungar (2011) cautions, "[t]hough patterns may emerge, the evidence encourages caution when asserting the generalizability of findings unless social and physical ecologies are held constant" (p. 7). Third, atypicality posits resilience-promoting strategies and resources are context-specific and that atypical behaviors, approaches, and resources may be adaptive in specific situations. The final principle is cultural relativity, which highlights the need to view resilience processes as culturally, temporally, and historically embedded. Barton (2005) similarly called for researchers to move beyond Euro-American understandings of resilience using a phenomenological approach that considers individual agency and broader structural factors, including processes used in everyday life (i.e., not only to overcome extreme hardship).

Scholarship pertaining to refugees' resilience has grown in the past decades. Research in this area has conceptualized resilience as protective factors (Carlson et al., 2012), as stemming from "everyday" processes (Lenette et al., 2013), as embedded in social networks (McMichael \& Manderson, 2004; Thomas et al., 2011; Tippens, 2020), 
and as shaped by cultural, social, and physical ecologies (Darychuk \& Jackson, 2015; Pulvirenti \& Mason, 2011; Tippens, 2017; Yotebieng et al., 2019). Although these highlight the importance of resilience as a lens to view refugees' positive adaptation in the face of adversity, there are critiques of how this framework has been applied to the study of forced migration. For example, Tippens (2020) cautioned there is need for nuance when considering refugees' "community resilience" as refugees often represent groups of individuals and families who are grouped together due to external factors (e.g., forced migration, peripheralized status in first asylum countries, governments' resettlement priorities). Labeling group-level processes as community resilience without contextualization may unintentionally obscure within-group dynamics. For example, Omata (2013) brought to light how expectations of resource-sharing among Liberians in a refugee camp in Ghana placed financial and material strain on refugees who themselves had scarce resources. These are necessary nuances to consider in resilience-focused inquiry with refugees and their families and communities.

\section{Method}

\section{Context and Setting}

This study was conducted in a midsized U.S. Midwest city that is home to the largest Yazidi population in the United States; a house-to-house census conducted in 2017 by refugee resettlement staff counted approximately 3,00o Yazidis live in the city. In addition to two resettlement agencies, there are three Yazidi-serving ethnic community-based organizations and multiple human service agencies with specific resources and services for refugees. The PI serves on a citywide refugee health coalition with members of these organizations. Stakeholders wanted to learn more about Yazidi women's health priorities to better meet the needs of this population.

The research team consisted of five women: the PI (J.A.T.)-the cofounder of the Midwestern Yazidi Society (MYS, name changed to protect anonymity; G.K.) - three female PhD students (K.R., I.P., K.K.), and a Yazidi undergraduate student (I.S.). The MYS cofounder is a Yazidi 
woman who was resettled to the United States with her family more than 15 years ago. MYS staff provide services for Yazidis, preserve Yazidi religious and cultural heritage, and raise awareness about Yazidis in the host community. It is possible participants perceived university researchers to work in refugee services and responded to questions accordingly, although we discussed our positionality during recruitment and onset of the project. The high educational and socioeconomic status of Yazidi co-researchers compared with many participants may have also influenced discussions.

\section{Study Design and Procedures}

Data collection was conducted for 16 weeks during summer and autumn 2019 and represents the preliminary phase of a broader participatory project in collaboration with the citywide refugee health coalition. We used photovoice to engage Yazidi refugee women and collect data pertaining to women's health and well-being experiences, perceptions, and priorities (Wang, 1999; Wang \& Burris, 1997). Participants take photographs representative of their experiences and discuss the meaning(s) of the images with fellow group members (Wang \& Burris, 1997). As a method, it has been successfully used to glean insight into refugees' and immigrants' health, well-being, and integration (e.g., Gomez \& Castaneda, 2019; Lenette et al., 2013; McMorrow \& Saksena, 2017; Pearce et al., 2017; Saksena \& McMorrow, 2020).

We worked in partnership with MYS to recruit women who were 19 years or older, Yazidi refugees, and fluent in Kurmanji. To address the limited research on older refugees, we held two groups with women; one group was recruited from the Yazidi "Granny Club," a biweekly social gathering for older Yazidi women sponsored by MYS. Adult women with school-age children were purposively sampled by MYS staff to understand how this group fared in resettlement. Older women's sessions were held at the church during their regular scheduled gatherings. Participants in the second group requested to meet in a classroom at the University of Nebraska-Lincoln given its central location. In addition to their research roles, Yazidi co-researchers provided interpretation for the two groups. We held eight photovoice sessions with each group, asking participants to take photographs related to a specific weekly prompt (Table 1 ). 
Table 1. Photovoice Sessions.

\begin{tabular}{|c|c|c|}
\hline Session No. & Activities & Topic(s) Discussed \\
\hline No. 1 & $\begin{array}{l}\text { Introductions (research team, participants) } \\
\text { Overview of photovoice project } \\
\text { Informed consent } \\
\text { Setting expectations } \\
\text { Photography-ethics, composition }\end{array}$ & $\begin{array}{l}\text { Describing health and well-being } \\
\text { Identifying health priorities }\end{array}$ \\
\hline No. 2 & $\begin{array}{l}\text { Printing photographs } \\
\text { Sharing images and group discussion } \\
\text { Reviewing major themes }\end{array}$ & $\begin{array}{l}\text { Health and well-being } \\
\text { in resettlement city }\end{array}$ \\
\hline No. 3 & $\begin{array}{l}\text { Printing photographs } \\
\text { Sharing images and group discussion } \\
\text { Reviewing major themes }\end{array}$ & $\begin{array}{l}\text { Describing meaning(s) of community } \\
\text { Identifying community challenges }\end{array}$ \\
\hline No. 4 & $\begin{array}{l}\text { Midpoint check-in } \\
\text { Printing photographs } \\
\text { Sharing images and group discussion } \\
\text { Reviewing major themes }\end{array}$ & $\begin{array}{l}\text { Identifying community strengths } \\
\text { and resources }\end{array}$ \\
\hline No. 5 & $\begin{array}{l}\text { Printing photographs } \\
\text { Sharing images and group discussion } \\
\text { Reviewing major themes }\end{array}$ & Cultural traditions and strengths \\
\hline No. 6 & $\begin{array}{l}\text { Printing photographs } \\
\text { Sharing images and group discussion } \\
\text { Reviewing major themes }\end{array}$ & $\begin{array}{l}\text { Cultural preservation and } \\
\text { new traditions in resettlement city }\end{array}$ \\
\hline No. 7 & $\begin{array}{l}\text { Printing photographs } \\
\text { Sharing images and group discussion } \\
\text { Reviewing major themes }\end{array}$ & Identity and belonging \\
\hline No. 8 & $\begin{array}{l}\text { Discussion of overall themes } \\
\text { Photovoice exhibit planning }\end{array}$ & N/A \\
\hline
\end{tabular}

Ethical approval was granted by the Human Participants Protection Program at the University of Nebraska-Lincoln. J.A.T. obtained written consent from women prior to the study. The informed consent form was read to women via an interpreter; we provided time after each section of the consent form for women to ask clarifying questions. Photo consent was obtained during the third meeting after women had taken photographs, so they would have a sense of what types of images would be shared. We were also sensitive about the potential for retraumatizing women, including our community partners, particularly concerning recent suffering related to the 2014 genocide. To account for this, we asked women if they would like to take a break after emotionally difficult conversations (with the option to stop for the day or change topics). We also asked our community partners to 
inform us if they noticed signs of distress that we might miss as cultural outsiders. Finally, we had information for community-based resources (including mental and psychosocial support services) available if needed. There were three emotionally challenging sessions during which women described surviving ISIL attacks and the distress they experienced during the time. Women asked to take breaks and used this as a time to provide comfort to one another; however, they always wished to stay and continue the discussion. Some women explained that although difficult, it helped share experiences with community outsiders.

Sessions were audio-recorded with permission, and two student research assistants took notes during the meetings, paying attention to both what women said as well as nonverbal cues such as body language, emotions, comfort with questions, and group dynamics. During the first session, we gave women digital cameras ( US\$40) to keep. Women in the younger photovoice group preferred to use their phone cameras and email photographs to the research team; however, we still gave them cameras as a gift for participation. MYS interpreters sent weekly text messages to participants reminding them to bring photographs to upcoming meetings. Women received US\$2O each week they brought photographs and received one personal photograph of choice at the meeting. Women who forgot to bring photographs but still participated in the discussion received US\$10. Photographs were printed on-site.

\section{Data Analysis and Dissemination}

As several participants described the photovoice project as a way to share their stories, we decided to use narrative analysis (Langellier, 1989, 2001) to guide the interpretation of data. Langellier (2001) stated that, "embedded in the lives of the ordinary, the marginalized, and the muted, personal narrative responds to the disintegration of master narratives as people make sense of experience, claim identities, and 'get a life' by telling and writing their stories" (p. 700). The research team met weekly to discuss initial codes and patterns based on women's discussions. Session transcripts and notes were transcribed verbatim and uploaded into the MAXQDA qualitative software package to assist with data management (VERBI, 2019). The PI (J.A.T.) and 
two graduate research assistants (K.R., I.P.) analyzed the final transcripts using Langellier's (1989) theoretical framework, paying particular attention to conversational interaction between participants and researchers as well as among participants themselves. They then met multiple times with Yazidi co-researchers (G.K., I.S.) to discuss images taken, how these related to the women's group discussions, the codes and preliminary themes generated by J.A.T., K.R., and I.P., and the broader sociopolitical and cultural contexts of Yazidis. Any inconsistencies related to interpretation of data were brought to Yazidi coresearchers for a final determination. We then brought these findings to Yazidi participants to ensure we had accurately interpreted their images and words, to ask whether there were images or photographs that women did not wish to share (e.g., in manuscripts or at conference presentations), and whether there was anything we had not captured.

In addition to "telling and writing their stories" (Langellier, 2001, p. 700), photovoice asks participants to show their stories. During the final session, we asked participants whom they wanted to show their photos. In both groups, women stated the urgency of being understood by members of the host community; as such, women asked to have an exhibit displayed at a World Refugee Day event in the state. ${ }^{1}$ This is a large annual event with music, dancing, and food that attracts large crowds. Findings have also been shared with members of the city's refugee health coalition to provide insight into women's health priorities and experiences.

\section{Findings}

Nine women participated in the photovoice project (older adult $n=$ 4). Women lived in the United States for a mean of 8 years (range = 2.75-21 years). Six participants were married, one was single, one divorced, and one widowed. Most of the participants had no formal education; the exception was a woman in the younger group who had been resettled as a teenager and completed college in the United States. Four women had lived in a refugee or internally displaced persons (IDP) camp in Syria, Turkey, or Iraq prior to resettlement (4 months-10 years). 
The initial questions we posed to women were "What does health and well-being mean to you and your community?" and "What are your health priorities?” (Table 1). In both groups, women centered on psychosocial aspects of health, including stressors such as trauma as well as the importance of family, community, and integration in overall well-being. Older women occasionally discussed physical ailments (e.g., gastrointestinal and digestive problems, diabetes) as related to overall health; however, they stated these were a natural part of the aging process and emphasized that psychosocial health and well-being were their primary concerns. Women selected images that best represented their responses to weekly prompts that (a) were not restricted to the time and location of the study and (b) were not always taken by the women themselves. For example, some women shared existing photographs they found from the internet, particularly if these showed images of Yazidis suffering at the hands of ISIL. Women described these images as best suited to capture what they lived through, even if they did not take these photographs.

We generated three themes based on the 16 total photovoice sessions with women: (a) trauma and cultural bereavement, (b) using naan (bread; as sustenance and symbol) to survive and thrive, and (c) preserving an ethnoreligious identity out-of-place. To protect the identity of participants, we do not use any identifying information. Similarly, we pixelated any identifying facial features in accompanying photographs. Although women gave us permission to use these images, we made this decision as many participants have family in Iraq and other countries; it was impossible for us to know what repercussions could occur if women's identities were to be revealed.

\section{Trauma and Cultural Bereavement}

Women in both photovoice groups overwhelmingly discussed trauma and distress related to the August 2014 ISIL attacks in the Sinjar region. Although not every participant was physically present in Sinjar during these attacks, each woman expressed sorrow related to personally witnessing death and suffering, distress over loved ones who had died in the attack or who remained in the region at great risk, or grief over ISIL's destruction of sacred Yazidi sites and the associated loss of ethnoreligious identity. To describe her personal experience 
fleeing the ISIL massacre, one 38-year-old woman selected a portrait by the photographer Rodi Said that had circulated several news outlets: a Yazidi woman holding a small child with two young girls beside her; out of focus is a line of Yazidis walking on the outskirts of the Sinjar mountains (Said \& Reuters, 2014). Referencing the photograph, she stated:

I could not cope when I was in the mountains. [Crying.] We saw children dying as we ran into the mountains. People put stones on [deceased children] because we did not have anything to bury them properly.... Nobody could bear to see what happened in Sinjar. It was so hard for me to see how children were thrown away because they died. Everyone was trying to find a way to survive. Mothers would cry and give their tears to their children so the children would not die from thirst. This is impossible to forget.

Responding to this story, other women in the session also participated in the conversation as a way to provide comfort as well as to shape the Yazidi narrative by providing additional context for the researchers. One of the woman's friends who also participated in the group explained, "[she] has had such a hard time dealing with this trauma. She comes to my home and talks about this all the time. She saw everything that happened [during the ISIL attacks]." A participant who was not in Sinjar at the time of the massacre nodded and shared information passed on to her by her family:

My relatives told me stories of how there was just a small lid [from a plastic bottle] of water and they would give one lid to every child so the children would not die. The children were taught after this to be so careful not to waste water. They appreciate water so much after this. Even in [the IDP camps], they would still use the lid to drink water until their mothers told them they could drink more, but not to waste any.

Separation from family members and loved ones was also a central cause of distress among participants. Women described this separation as being "less than whole," as missing a part of oneself, and 
as feeling out-of-balance. A woman in her early 6os noted, "Most [Yazidis] are tired and have low self-esteem. We are depressed because when we were scattered, it was not something we had planned for. We did not have a chance to say goodbye or to have a proper farewell." Most of the women described an ever-present fear for loved ones who remained in northern Iraq and were potentially in danger. One participant took a self-portrait that showed her reclining on a sofa, drinking coffee, and talking on the phone. She described why this daily ritual was critical to her well-being:

Whenever I am on the phone with my son, it is a happy time for me because at that moment I know that he is alive, that [ISIL] has not harmed him, and that everything is alright. [. . .] When we were accepted to the U.S. [refugee resettlement program], my son was 21 and was not accepted to come with the family because of his age. Now he lives in an IDP camp in northern Iraq. There are too many problems in the camp. Because I worry, I always have to take medicine to fall asleep. [The U.S. and Iraq] are not in the same time zone; if something happens in Iraq, it will already have passed by the time we learn of it in the U.S.

Women in both the older and younger groups similarly discussed the importance of technology to connect with family who remained in Iraq, were living in neighboring countries, or who had been resettled to different countries such as Germany or Australia. Family separation also affected daily living in the United States. For example, older adult women who were resettled without family talked about family separation as resulting in overall social isolation in the United States, despite the presence of a larger Yazidi population in the city. Older women found their family and social roles changing, and lost roles such as respected elder and grandparent, a finding consistent with older refugee women's experiences and perspectives in previous studies (Dubus, 2010; Lewis, 2008). They were also forced to provide for themselves in older age whereas if they remained in Iraq, they would be cared for by-and likely living with-younger family members. In such instances, older women relied on others from their ethnic community for social and emotional support. A divorced participant in her 


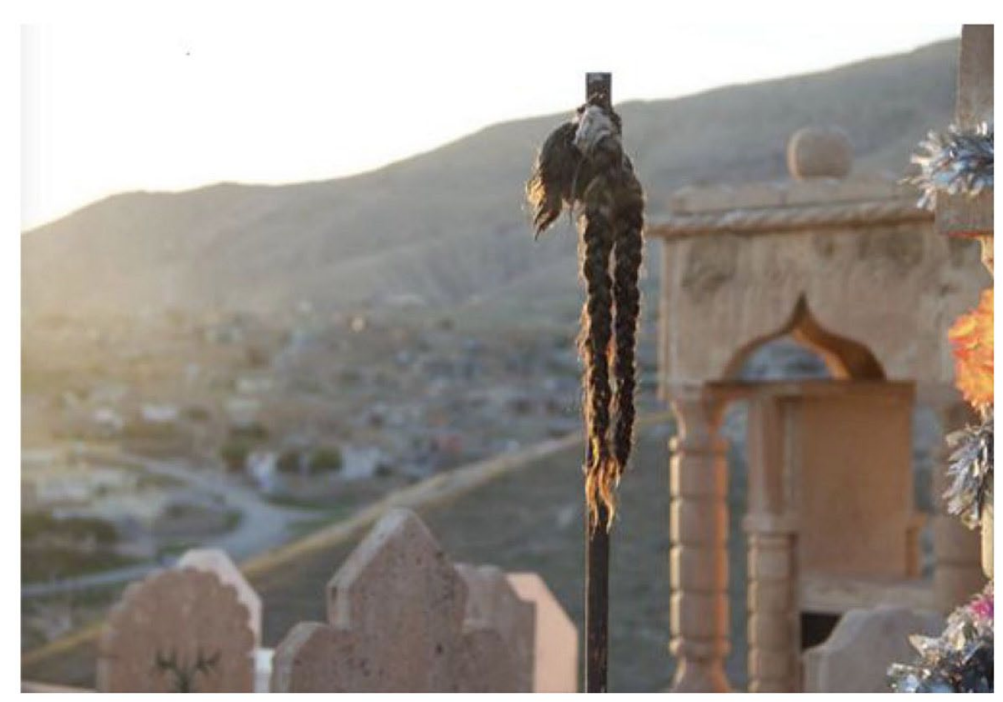

Figure 1. Braided hair at cemetery in northern Iraq. Note. After the death of a loved one, Yazidi women may cut their hair and hang it at the cemetery as a symbol of loss and departed beauty.

late 6os who resided by herself in a one-bedroom apartment said the MYS "Granny Club" was her only opportunity to socialize with other women from her community; she relied on the twice-weekly gatherings for emotional support.

Bereavement in a new host country was another stressor for women. One older woman's sister died of cancer in Iraq shortly before the onset of the study. The participant described the immensity of her grief due to her sister's death as well as her inability to mourn with family using familiar rituals. Her only solace during this time was the presence of a Yazidi cemetery that had been built by the community just outside of the city: "Sometimes what brings me relief is when I go to the cemetery and just sit there and cry." In the younger adult women's group, a participant in her 30 similarly described the importance of having a sacred place to grieve the loss of loved ones. She showed a photograph she had taken at a cemetery in northern Iraq during a visit to see her family (Figure 1). The participant said that, traditionally, Yazidi girls and women do not cut their hair unless a loved one passes away. After the death of a loved one, they would cut long braids and place them by the headstones of the departed: "In our culture this act is a way to say, 'the beauty in my life left with 
your departure' when those we love pass away." She further shared that many Yazidi women continue to practice this ritual at the community cemetery in the resettlement city: "Here, when you see a [Yazidi] woman wearing her hair short, it means she recently lost someone."

In addition to bereavement and grief over the loss of family members, women discussed a sense of losing their cultural identity in a new country. A woman in her 30 described this sense of liminality:

For me, as an immigrant to the United States, one of the things you feel no matter how old you were when you came to the United States, is the feeling of ... I don't know, like you're missing something, always ... being far away from your culture, your land, your community.

Participants expressed conflicting perspectives related to cultural loss. Women described a sense of gratitude being able to practice Yazidism, speak Kurmanji, and celebrate important holidays after centuries of persecution and having to hide their ethnoreligious identity in Iraq. However, this new ability to openly practice Yazidism was hampered by both a desire to fit in within the host community and a fear that children would forget about their cultural heritage because it is not part of the public school curricula. All of the women expressed a strong desire to have a Yazidi temple built in the city on the same grounds as the cemetery. In addition to serving as a place of worship, Yazidi women shared ideas of how a temple could be used for community celebrations, children's education (culture, religion, language), and educational events for members of the host community who wanted to learn more about Yazidi refugees. Participants in both groups excitedly shared photographs of a Yazidi temple recently built in Armenia; the erection of an important cultural and religious monument outside of Iraq provided a sense of hope for the preservation of Yazidism among members of the diaspora.

\section{Naan (as Sustenance and Symbol) to Survive and Thrive in Displacement}

"Naan is sacred for Yazidis. If it were to fall on the floor, we would pick it up, kiss it, and ask for forgiveness." 
Naan as survival. Women discussed naan, a flatbread and staple food for Yazidis, as both sustenance and symbol during each of the 16 photovoice sessions. A participant in her 40s who survived the 2014 ISIL massacre discussed how bread was central to survival during monthlong displacement in the Sinjar mountains:

If we think about the most recent genocide [August 2014], naan helped many people survive in the mountain. I ran to the mountain with many others to escape ISIL. We grabbed bread and flour. We shared this bread and survived on it. When there was no more bread, we used the flour to make more. And when there was no more flour, some of the men would leave the mountain to collect wheat from the nearby fields. The women cooked this and we ate it to survive. We used what we had from the land.

The participant's description of using naan for survival is reminiscent of Atallah's (2017) reporting on the resilience of displaced Palestinian families living under Israeli occupation. Atallah described how the act of collecting foods from occupied lands to prepare "meals of resilience" were "sources of empowerment in coping with both hunger and historical trauma” (p. 370).

Naan as symbol of cultural values and expectations. Beyond the value of naan as a source of survival, discussions of the flatbread symbolically mirrored Yazidi cultural values and expectations such as generosity, reciprocity, and forgiveness. Throughout the duration of the study, women spoke about the significance of generosity in Yazidi culture, particularly the importance of sharing resources with individuals and families in need. For example, when she shared how one of her friends (also in the group) was changed by the 2014 ISIL massacre in Sinjar, one participant in her mid-3os invoked naan as a symbol of her friend's generosity and compassion before the genocide:

[She] is a very genuine and generous person. She was my neighbor [in Iraq], and she used to give naan and food to the poor people all the time. When she found people who needed something, she would give everything she had to help them. 
Several women discussed the tradition of making extra food during holiday celebrations so there would be leftovers to share with those in need. The research team also noted that many women talked about sharing weekly cash incentives with people who were going through challenging times. These actions in tandem with the women's descriptions of naan indexed the cultural importance of generosity and compassion.

Women also emphasized the importance of reciprocity in Yazidi culture and noted this was lacking in their U.S. integration experiences. Many participants expressed surprise that the host community largely did not know about the Yazidis, considering many were resettled under the Special Immigrant Visa (SIV) program for interpreters who served in the U.S. Armed Forces. Some women said they felt hurt and betrayed that members of the host community were not interested in developing friendships with the Yazidis after they had put their lives in jeopardy to serve alongside American soldiers. A woman in her 40 s described her attempts to develop close friendships with members of the host community, and used naan as a metaphor for feeling misunderstood by Americans:

We have a cultural aspect to food when we make warm bread. When we finish baking, we have to share what we make with someone, even if it is just a relative like an aunt or to the animals roaming the street or to a neighbor. Sometimes I give it to our American friends. They say "thank you," but do not understand our culture.

During one of the photovoice sessions, the same woman was visibly upset during the group due to what she described as an altercation with an American friend. She did not understand what happened to end the friendship: "This was such a shock to me. In our culture and religion, forgiveness is so important. If he were part of my community, he would have forgiven me. A friendship so strong and so beautiful would be able continue." One of the other women listened intently to this story, adding as follows:

In our culture, if you take naan to a neighbor and they accept it, there is a mutual feeling of friendship. But if they do not 
accept it, it means that they have not opened their hearts to you. [After an argument,] they might accept it, meaning, "I forgive you."

She noted this is particularly true when naan is given during the holidays. Yazidis give naan with fruit and candy as a way of strengthening or rekindling friendship. She added, "sometimes it might be given just because everyone loves fresh naan."

Naan as integration and intergenerational nurturing. Finally, participants discussed naan as related to their broader well-being and integration. Although there exists no agreed upon definition of refugee integration, it is a multifaceted concept that broadly entails a sense of belonging in the host community without relinquishing one's cultural values and practices (Ager \& Strang, 2008; Strang \& Ager, 2010). Women who participated in the photovoice project expressed a sense of pride regarding their ability to preserve Yazidi culture as well as to integrate into the host community through naan. Women remarked that making naan was difficult in the United States and stated that they adjusted cooking methods to accommodate both a lack of time and a harsh winter climate. Although it was customary to make naan every morning in Iraq, women found this to be an impossibility in the Midwest United States. Most women cooked in garages using tandoor ovens; the gas barrels freeze during colder months, and women made enough to last for at least a month or two at a time (Figure 3). The skills required to make "good" naan were highly valued by participants and, in each of the groups, there was one woman identified as the "best at making naan" (Figure 4). In addition to baking naan for cultural and religious celebrations, some of the women made naan for events in the host community, which was described with great pride. For example, a woman in her 30 discussed a photograph she took of her tandoor oven to share a story of being invited by an American pastor to teach members of the congregation how to make naan (Figure 2):

There was a church that asked me to teach the members how to make this bread and I agreed. When I made it, all of them came too close to the oven, not realizing how hot it was. I told them, "No! Don't do that!” They were so scared 


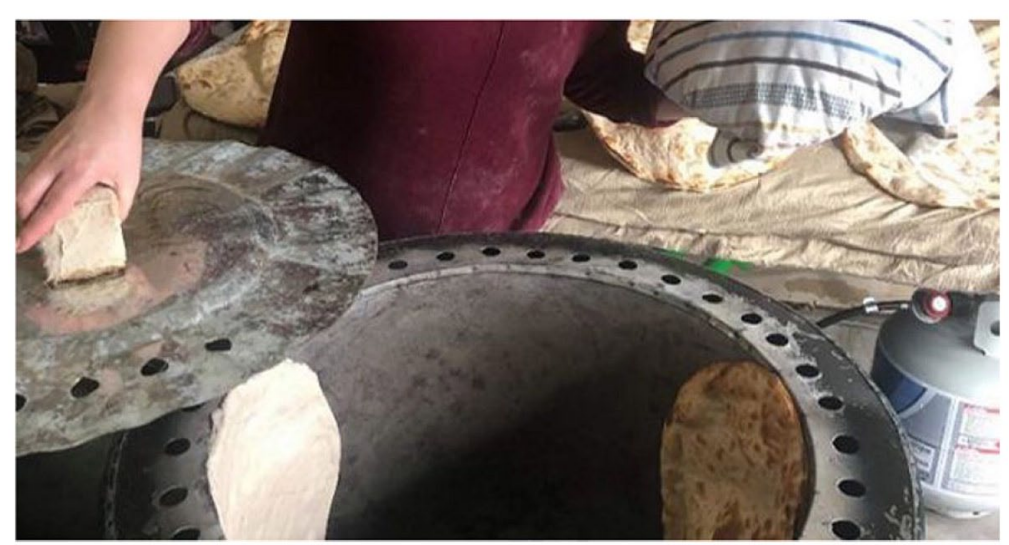

Figure 2. Tandoor oven. Note. Traditional ovens are available for purchase at a Yazidi-owned store in the resettlement city. Women in the city typically make naan in their garages.

because I told them to stay away from the oven. [Laughs.] They wanted to know how I put the bread in and then take it out of the [tandoor] oven. After I told them not to come too close to the oven, they were all so scared. There were about 20 people. I also made yogurt. We [share food with Americans] a lot. When we share these foods, everyone is so happy.

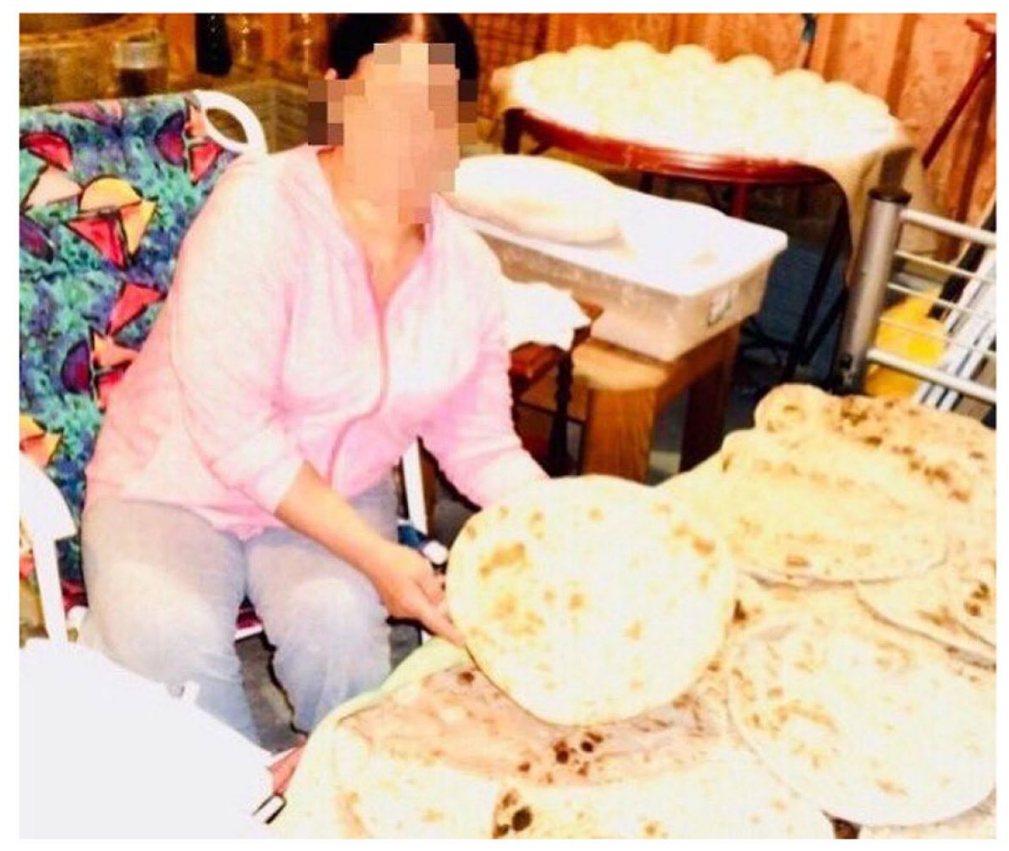

Figure 3. Woman making naan. Note. A woman prepares a large batch of naan to last for the winter months. In keeping with cultural traditions, Yazidi women frequently share freshly prepared naan with their American neighbors. 


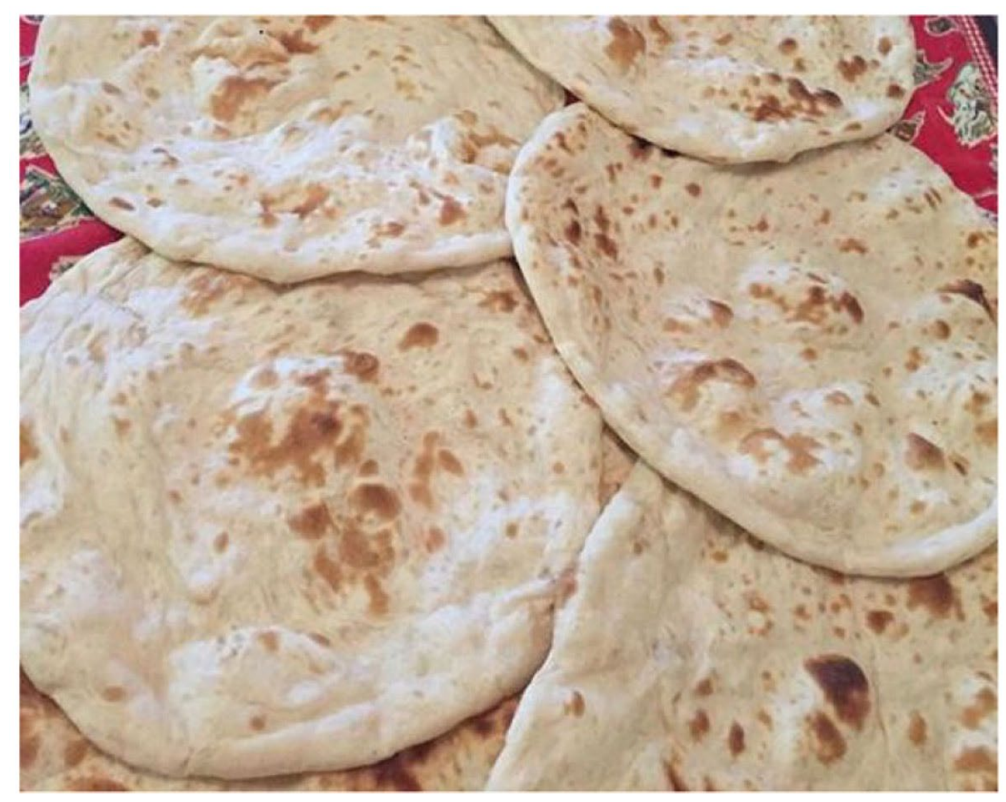

Figure 4. Freshly prepared naan. Note. The ability to make naan is highly valued among Yazidi women. This was prepared by a woman who was said to be among the most skilled at making naan.

This provides an example of integration as a bidirectional process in which im/migrants and refugees share their cultural expertise and traditions to foster social ties with members of the dominant host community. Similarly, although we provided food during photovoice sessions, Yazidi women often brought traditional foods such as naan, sweets, and tea to share items they enjoyed with the U.S.-based researchers.

In addition to using naan to connect with members of the host community, women described how naan was used as a form of nurturing, both the literal ability to feed children and the symbolic value of naan as preserving Yazidi culture through intergenerational exchange (e.g., teaching children to make naan). A participant in her 20 s described how the act of making naan was important because it meant she was able provide for her children: "When I make bread it's a relief. To be able to make food and feed and take care of my children is a relief for me." Other women with young children talked about the joy of passing down culinary traditions in a new country. Participants learned how to make naan in Iraq alongside their mothers and aunts as young girls. It was important for them to continue this practice 
with their own children, especially their daughters. A woman in her late 3os agreed and talked about teaching her children to make naan: "My daughter says she wants to make the bread like me, but she is still young. Sometimes my children will practice [making naan] with playdough." The act of cooking was seen as important; so too was passing along respect for the cultural value of naan among Yazidis. A participant in her early 30 said,

Naan is important to Yazidi families. We make bread and we even give it to other people. You cannot throw away bread. If you make naan and someone throws it or steps on it or something, it is not acceptable. If it falls on the floor, we pick it up and kiss it. This is how we teach our children to handle bread.

In her extensive ethnographic work with Turkana pastoralists in Kenya, Pike described how Turkana women's ability to nurture children provides insight into resilience processes beyond food itself: “... ruptured families require reconstitution in order to maintain or even re-create the social systems required to rear children. Evaluating how these practices transform provides us with a deeper understanding of women's resilience" (Pike, 2019, p. 127). Pike's depiction of nurturing as resilience provides insight into how Yazidi women have reconstructed their lives to maintain important values and practices within the context of negotiating a new cultural landscape.

\section{Preserving an Ethnoreligious Identity Out of Place}

The importance of ritual and routine in promoting resilience.

To counter the loss of an ethnoreligious cultural identity in a new place, all Yazidi women noted the importance of celebrating holidays with other members of the community. Most participants said that their favorite event was the Yazidi New Year, or Sere Sal (literally "head of the year"). New Year celebrations are held annually in April at a park in the resettlement city. Women discussed enjoying wearing pastel dresses symbolizing spring and rebirth, sharing food with family and community, dancing to traditional music, and the promise of warmer weather. Celebrating Sere Sal and other religious holidays also provided an opportunity to pass cultural heritage to children out 
of place. A woman with three young children noted, "We have holy days that we teach our children about. They know that we have these holy days and they learn about the religion and spend time with others in the community during these days."

Women in both groups also discussed the importance of dress to Yazidi life. Older women wore long gowns and light-colored headscarves to weekly sessions, noting the white or light blue color of their scarves symbolized peace. Although women in the younger photovoice group did not wear headscarves, they did dress modestly by mainstream U.S. standards. When we asked about headscarves, the younger women responded that older women wore these either to cover gray hair or due to cultural norms. During the broader conversation about clothing, women with young children expressed sadness that they did not know how to sew dresses by hand as their own mothers had done for them. Child-rearing out-of-place seemed to intensify emotions related to family separation and culture loss. Traditional clothing, the women explained, must be made by Yazidi seamstresses or tailors; in a smaller community outside of Iraq, it was difficult to find people qualified to sew traditional garments. One participant shared how another woman in the group was a skilled seamstress and joked, "If you go to her home at night, you'll feel like you're in Lalish [because] the children are wearing traditional dresses!" This sparked a conversation among the two women, both in their 30 s with school-aged children, about traditional dress for younger Yazidis:

Woman A: We should not forget about our traditions and our religion just because we have moved. The dress is part of this.

Woman B: For me, personally, the dress is not that important. Our faith is inside-in my heart and in my mind. This is what I think is important.

Woman A: I think both are important. Showing your faith and also knowing in your heart.

Woman B: My children don't know a lot about the cultural style of dress for Yazidis. [Woman A's] children do. But there are different groups within the Yazidis with different traditions. Some groups have more of a commitment to traditional dress, but not all of us do. But all of us hold our faith in our hearts. 
As the second woman noted, the reason for disagreement regarding the importance of traditional dress to promote religious identity may be explained by different cultural groups. It should also be noted that Woman A is a newcomer to the United States and has lived here for only 3.5 years compared with Woman B who has resided in the host community for twice as long. Women must negotiate which elements of their cultural heritage can be maintained out-of-place and it is possible that, over the years, this was a tradition that the second woman stopped for convenience. Whereas community celebrations, traditional dress, and favored cultural foods were identified as important ritual elements to preserve the Yazidi identity, prayer was discussed as an important daily routine that helped women make meaning of adversity, cope with stress, and feel a sense of belonging to the larger transnational community. Older women also discussed how they used religion to provide a sense of order and time out of place. For example, fasting was used to remind them of upcoming holidays, and daily prayer helped establish a daily routine. A woman in her mid6os shared an image of her praying (Figure 5) in front of the khalat, stating:

This is me inside my house. The khalat is the sacred item behind me. It faces the sun. When I pray, I also face the sun. When [Yazidis] make this gesture [open hands, palms upward], we are asking God for help. In the other [head bowed], we are bowing to god. The round pellets are called barat and are made from soil and water from our holiest center, Lalish. These are made from the holiest water and soil from the springs near Lalish. I carried these with me from home... . For us, we say that the sun is the light of God. This is another reason we face it when we pray.

She continued, taking great pride in sharing her prayers with the researchers:

There is a specific prayer that Yazidis pray all the time. We ask God to please protect all of humanity. Then we pray for the animals, for those who are in prison, for those in captivity, and then for other people going through hardship. 


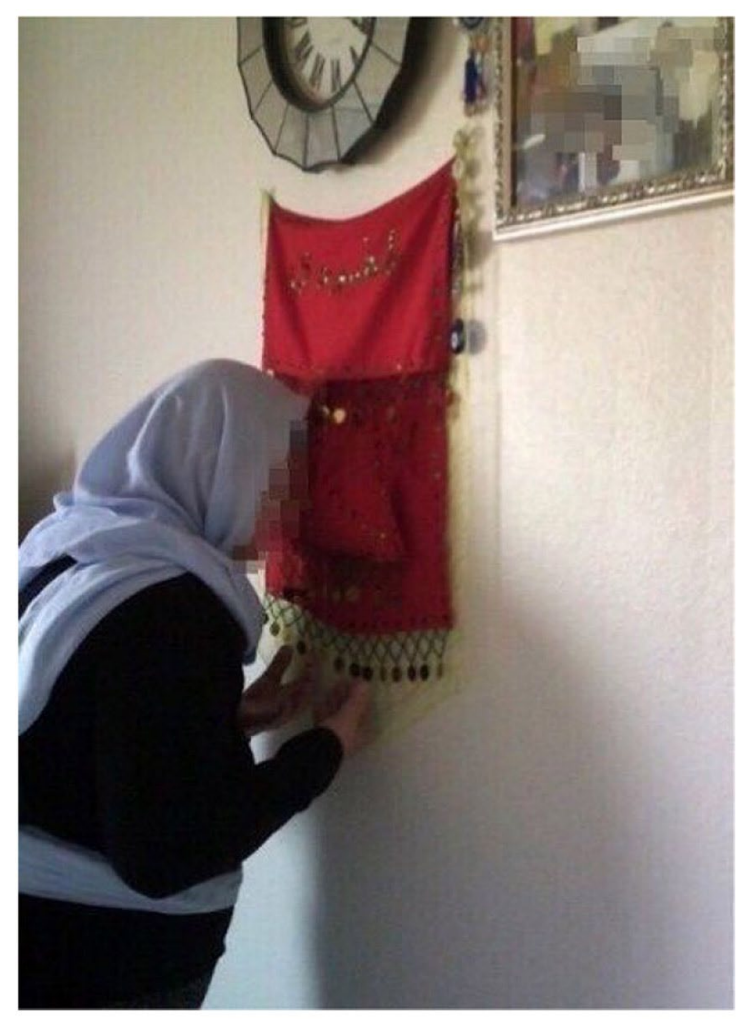

Figure 5. Evening prayer. Note. Yazidi woman praying in front of the khalat, or prayer tapestry. The barat, small pellets made from sacred soil and water from the holy center Lalish, hang from the khalat. Many women said this was one of the few things carried with them to the United States.

Finally, at the end we ask God to please include us. [Interviewer: So, this means you (Yazidis) are always last in the prayer?] Yes! We fit in afterwards. [Pauses] But since the genocide happened, we always pray for ourselves first! [All of the women laugh.]

Establishing boundaries to preserve a collective identity.

Participants expressed pride in a distinct ethnoreligious identity, and continually noted the centrality of language and religion in this identity. Kurmanji, the language that unites the majority of Yazidis, is classified as a northern dialect of Kurdish (Ludwig, 2008); however, Yazidi women contested this, declaring Kurmanji a separate language entirely and not merely a dialect. Language was cited repeatedly during groups as important for both practical reasons (e.g., medical 
interpretation) as well as for reasons related to collective identity. Many women shared memories of being forced to use Arabic or Kurdish as using Kurmanji would put them at risk as an ethnoreligious minority group. Participants expressed happiness about being able to speak Kurmanji freely in the United States and described their ethnicity, religion, and language as inseparable. During one session, a participant in the "Granny Club" group made a fist and hit the desk, proudly exclaiming as follows: "I am not an Arab! I am not a Kurd! I am a Yazidi!"

Women repeatedly discussed the preservation of a collective Yazidi identity as central to both individual and collective well-being. Although participants expressed an openness to friendships outside their ethnoreligious group, women of all ages emphasized the importance of marrying within the Yazidi community. A woman in her 20 s said the following:

The first thing children need to know is the mother's language. They have to know the language of our community. The second thing is religion; we need to teach our children that they can only marry within our religion. We love and respect all religions, but one cannot marry outside of our religion and one cannot simply be Yazidi or convert to Yazidism.

Women further described that marrying within the religion was a critical element to preserve Yazidism. Due to restrictions on joining and returning to Yazidism, marriage within the religion is one of the only ways to preserve Yazidism. A woman in her 40 os provided additional context to the research team:

Woman: $\quad$ Many people ask us, "Why is it that your children do not marry people from other religions?” ... Yazidis can leave the religion but nobody can convert to Yazidism. And if a Yazidi leaves the religion, they cannot convert back.

Interviewer: How does this affect families? Can they still have relationships with those who have left Yazidism?

Woman: No. There would be a concern that other family members would follow and also leave Yazidism. The only exceptions are the women who were kidnapped by ISIL 
and forced to convert to Islam. Those who have escaped and returned have been permitted to convert back to Yazidism.

After she spoke, women had a conversation among themselves pertaining to whether children of women abducted by ISIL as sex slaves would be accepted into the community. Women did not come to a clear consensus. Although it was evident that participants felt a strong desire to preserve Yazidi religion and customs, there was clear apprehension about this scenario because Yazidis cannot have sexual contact with a non-Yazidi or outside of marriage without community ostracism.

As discussed by Kizilhan (2017), there is an unambiguous Yazidi caste system that prohibits marriage between groups and, in a sense, provides guidelines regarding with whom one can have a relationship. These rules are not generally contested as it is accepted that one is born into a certain caste. Typically, sexual contact with a non-Yazidi or outside of wedlock would result in community rejection. However, after the widespread sexual assault and rape of Yazidi girls and women by ISIL, many communities have had to reconsider the rules of shunning (Kizilhan \& Noll-Hussong, 2017). Yazidis are faced with the challenge of maintaining long-standing religious and cultural expectations while facing the horrors of large-scale sexual assault and rape of Yazidi women and children. Resettlement has also posed challenges to premigration ideals; women discussed the desire for their children to marry Yazidis within their caste while acknowledging the difficulty of continuing such traditions within a smaller community in the United States. Women expressed a desire to preserve Yazidism through prayer, cultural traditions, and marriage. In the context of resettlement, they have been forced to navigate new pathways that situate familiar rules with new, unfamiliar terrains.

\section{Discussion}

In this study, we simultaneously sought to identify Yazidi women's health and well-being priorities and explore the social, cultural, and structural determinants of resilience. Yazidis comprise a significant 
proportion of refugees in the United States, yet there is little known about how this ethnoreligious minority group copes with trauma and adversity to promote positive individual, family, and collective wellbeing. Indeed, to our knowledge this is the first study with Yazidi refugees in the United States. Wexler et al. (2009) called for public health researchers to more carefully consider the nuances of resilience among marginalized groups. We heed this call, noting the importance of research on trauma among Yazidi women, but also providing a new, contextualized perspective on how Yazidis endeavor to overcome adversity. Utilizing a participatory research approach helped us glean critical insights into women's perspectives of challenges and strengths. Holding eight sessions for each group was an important part of this research. Women were initially hesitant to talk about any difficulties they experienced in resettlement and often highlighted how grateful they were to Americans; we attributed this to social desirability bias as many members of the research team represented the majority (White) population in this Midwestern U.S. city. Women were less reticent after the third session. To address these expected challenges, we repeated some of the questions from the first two sessions during discussions in later sessions. Overall, women said they enjoyed participating in this project, particularly opportunities to discuss memories and photographs with other women, share cultural traditions and food with the researchers, and identify community strengths and resources in overcoming hardships. We believe photovoice is a promising method to use with refugees. We noted earlier that women's photographs transcended time and place; it is our perspective that photovoice studies with refugees, therefore, should emphasize flexibility in allowing participants to define "community" (i.e., postmigration resettlement community, premigration community, or a combination) as they see fit for the project. Had we limited questions or images to the U.S. resettlement context, we would have missed important historical, sociopolitical, and cultural insights that have permeated into women's experiences in the host society.

Yazidi participants in this study discussed how trauma, particularly the 2014 ISIL genocide, has adversely affected their overall health and well-being. The deleterious effects of the genocide have been documented elsewhere (Gerdau et al., 2017; Kizilhan et al., 2020; Kizilhan \& Noll-Hussong, 2017; Nasıroğlu \& Ceri, 2016; Tagay et al., 2017); it is critical for refugee health and service providers to understand how 
the ISIL genocide has affected the health of Yazidi survivors as well as members of the diaspora who were not physically present during the massacre (Tagay et al., 2017). Women also emphasized elements of cultural bereavement that have not been taken into consideration in previous mental health studies with this population. Many women expressed distress pertaining to fear of losing Yazidi culture, feeling isolated or separated from cultural values, sensing that their culture was fading out-of-place, or experiencing continued liminality because their efforts to connect with the host society were neither fully understood nor reciprocated by many Americans. These factors may explain, in part, women's emphasis on cultural identity mobilization and the importance placed on within-group belonging (e.g., Kevers et al., 2017). Mobilizing a Yazidi identity in resettlement may also be a form of resistance-as-resilience. For example, demonstrating pride in a previously "forbidden" identity and wanting to share experiences of human rights violations with new American neighbors may be ways to show power over their oppressors in addition to finding places of belonging.

Consistent with Ungar's (2011) principles of resilience, Yazidi women in this study demonstrated how resilience processes are embedded in history, temporality, and culture. Women utilized familiar social practices in an unfamiliar terrain to negotiate and create a livable environment out-of-place. For example, women used naan to impart their values in the dominant host society as well as to pass cultural wisdom and traditions to younger generations of Yazidis. Many women described sharing naan with American neighbors as a way to actively engage with the host community. Although this demonstrates how women leveraged familiar cultural practices to promote resilience, researchers caution against simplistic interpretations of culture in resilience studies. In their research on Afghan youths' resilience, Panter-Brick and Eggerman (2012) noted that culture can also be a form of "entrapment":

Culture may be essential to forming one's social identity, sense of order, and hope for the future-but people suffered great psychological distress when they found themselves unable to conform to the high standards of "what makes an honorable Afghan.” Adherence to Afghan cultural values could thus bring about intense hardships. Failure or 
frustration in attaining social and cultural milestones was articulated in local idioms of stress, anxiety, and depression, or conflicts that are debilitating and life threatening. (p. 383)

Theron and Liebenberg (2015) also urged researchers to account for the complicated matrix of resilience experiences. Indeed, these complexities around resilience were clear in our study with Yazidi women. Although women in our study utilized culturally embedded strategies to promote resilience in a new place, they expressed displeasure when their cultural expectations were not met within the host society. Participants were dissatisfied when their generosity (e.g., sharing naan) was not understood or not reciprocated by Americans and hurt by limited opportunities for friendship with members of the host community after Yazidis had served alongside Americans with the U.S. Armed Forces. Similarly, their desire to maintain an endogamous Yazidi people through marriage was complicated by the reality of living out-ofplace in a city with only 3,00o Yazidis. Women with younger children contended with this reality, fearing not being able to raise truly "Yazidi children" who would strictly adhere to stringent cultural standards.

Despite challenges, women demonstrated courage and creativity every day to foster viable lives for themselves and their communities through typically gendered work: passing traditions to the next generation, instilling Yazidi values in children, and contributing to Yazidi cultural festivities (e.g., sewing traditional garments; making feasts, including naan). This is consistent with Darychuk and Jackson's (2015) findings from their research with Palestinian refugee women: "Because their community action takes place in the social world, rather than economic or political, reproducing stories and placing importance on the collective were the most salient ways women saw to contribute to community resilience and reproduce national identity" (p. 452). This work was also instrumental in the survival of Yazidis while displaced in the Sinjar mountains. As explained by one of the women, Yazidis gathered wheat from nearby fields to prepare what Atallah (2017) termed "meals of resilience," which kept them alive in the absence of other food sources. Participants' depictions of resilience across time and place are an important contribution to the literature that contextualizes refugees' resilience processes in resettlement settings. Additional research is needed to capture resilience among Yazidi 
refugees in the United States more broadly to further contextualize how resilience is understood and enacted by female and male Yazidis from different castes, age groups, and so forth.

\section{Study Limitations}

Although this study contributes important information, it is not without limitations. We used convenience sampling to recruit participants; as such, there is variation in the length of time women have resided in the United States (2.75-21 years). Undoubtedly, length of time in a host country has an influence on refugees' access to resources, coping strategies, and experiences in the community. Our recruitment strategy made it impossible to comment on how length of time in the United States influenced resilience processes.

\section{Implications}

Our findings have important implications for broader mental health and psychosocial support (MHPSS) research and practice with displaced communities. This work highlights the oft-overlooked crevices in which refugees contend with past trauma, present discrimination, and ongoing cultural bereavement to carve out viable lives in postmigration settings (i.e., resilience). As Hendrickson et al. (2018) noted in their study on Nepali widows' resilience, the strategies that women used to shape resilience occurred in conjunction with women's grief and other struggles, revealing how resilience processes and adverse circumstances are inextricably linked. This study occurred during a simultaneous period of unparalleled global forced displacement and decreasing empathy toward persons fleeing persecution and seeking sanctuary. Specifically, in the country of research, the Trump Administration had enacted the "Muslim ban" that was broadly meant to curtail immigration (including resettlement) to the United States among Muslims, but also affected Christians and religious minorities from Muslim-majority countries (Brayman, 2017). ${ }^{2}$ These broader political contexts are important determinants of mental health, merging with cultural bereavement and resilience in shaping refugees' postmigration experiences, including how they make meaning of premigration trauma and suffering. 
Importantly, Yazidi women shared stories of naan to index cultural values as well as to communicate suffering, bereavement, and resilience. Two women discussed naan as a metaphor for intergenerational resilience while one described how her enviable skills making naan enabled her to interact with members of the host community. A different participant used depictions of naan to describe Yazidis' survival in the mountains as well as to communicate distress over the loss of a friendship and general unease in an unfamiliar environment. These rich, sometimes contradictory depictions of naan extend beyond food and evoke Nichter's (1981, 2010) work on idioms of distress. In his reflection of three decades of an idioms of distress research agendum, Nichter (2010) described the importance of recognizing idioms to establish rapport with patients in clinical settings and in providing socioculturally informed care management. We believe this is true for both mental health providers working with Yazidi clients and refugee social service providers working at family and community levels. This can be accomplished through cultural consultations, assessments informed by both psychiatric and cultural expertise and completed with input from a wide range of stakeholders (e.g., clinicians, cultural liaisons, social workers, interpreters, protection officers; Kirmayer et al., 2014a). Future research with Yazidi refugees should examine the feasibility, acceptability, and effectiveness of culturally-informed clinical and community mental health interventions that leverage cultural strengths and resources.

Women's resilience was supported by larger community structures. For example, the Yazidi cemetery provided a venue for refugees to continue familiar bereavement traditions as well as a place for women to make meaning of the grief associated with transnational loss. Women's desires to erect a Yazidi temple highlight the importance of placemaking in collective healing, well-being, and identity. Resettlement providers and refugee-serving community organizations may wish to work with community leaders to identity funding opportunities to assist refugees with long-term planning efforts (e.g., the U.S. ORR funding mechanism for the Ethnic Community Self-Help [ECSH] Program). 


\section{Conclusion}

Genocide and forced migration place refugees at risk for poor physical and mental health. In this study, nine women described how they overcome hardship and adversity to promote psychosocial resilience. Using narrative analysis, we generated the following themes: (a) trauma and cultural bereavement, (b) naan (as sustenance and symbol) to survive and thrive in displacement, and (c) preserving an ethnoreligious identity out-of-place. Women's efforts to carve out spaces to continue important cultural rituals and routines that foster collective resilience were laudable. Importantly, our findings from this project overlap with and diverge from previous research on refugee resilience. This highlights the diverse ways refugees overcome adversity, make meaning of trauma, and create viable lives in postmigration settings. Recognizing and supporting these different processes is critical to enhance the well-being of refugee groups in U.S. resettlement.

Acknowledgments The authors are grateful to the women who participated in this study as well as their community partners who helped them navigate new relationships. The authors are also thankful for thoughtful feedback from reviewers, which greatly strengthened the final version of the manuscript.

Conflicting Interests The authors declared no potential conflicts of interest with respect to the research, authorship, and/or publication of this article.

Funding The authors disclosed receipt of the following financial support for the research, authorship, and/or publication of this article: This research was supported by a University of Nebraska- Lincoln Layman grant awarded to J.A.T.

\section{Notes}

1. At the time of writing this article, the World Refugee Day 2020 event had been postponed due to Coronavirus 2019 (COVID-19). We are working on alternative exhibits.

2. Perhaps unsurprisingly, we had conversations during this period with many members of the Yazidi community who supported the Trump Administration, recalling public comments the former president made rebuking the Islamic State and promising to fight "radical Islamic terrorism." As Yazidi families began to be personally affected by the ban and hopes for family reunification were diminished, we noted this support became less widespread. 


\section{References}

Ager, A., \& Strang, A. (2008). Understanding integration: A conceptual framework. Journal of Refugee Studies, 21(2), 166-191. https://doi. org/10.1093/jrs/feno16

Al-Khalidi, A., Hoffmann, S., \& Tanner, V. (2007). Iraqi refugees in the Syrian Arab Republic: A field-based snapshot. Brookings Institution; University of Bern Project on Internal Displacement.

Allison, C. (2017, January 25). The Yazidis. Oxford Research Encyclopedia. https://oxfordre.com/view/10.1093/acrefore/9780199340378.001.0001/ acrefore-9780199340378-e-254

Atallah, D. G. (2017). A community-based qualitative study of intergenerational resilience with Palestinian refugee families facing structural violence and historical trauma. Transcultural Psychiatry, 54(3), 357-383. https://doi. org/10.1177/1363461517706287

Baarnhielm, S., Laban, K., Schouler-Ocak, M., Rousseau, C., \& Kirmayer, L. J. (2017). Mental health for refugees, asylum seekers and displaced persons: A call for a humanitarian agenda. Transcultural Psychiatry, 54(5-6), 565-574. https://doi.org/10.1177/1363461517747095

Barton, W. H. (2005). Methodological challenges in the study of resilience. In M. Ungar (Ed.), Handbook for working with children and youth: Pathways to resilience across cultures and contexts (pp. 135-147). SAGE.

Basci, E. (2016). Yazidis: A community scattered in between geographies and its current immigration experience. International Journal of Humanities and Cultural Studies, 3(2), 340-351.

BBC. UN Security Council condemns attacks by Iraqi jihadists. (2014, August 7). BBC News. https://web.archive.org/web/20140808001143/http://www.bbc. com/news/world-middle-east-28699832

Bhugra, D., Gupta, S., Bhui, K., Craig, T. O. M., Dogra, N., Ingleby, J. D., . . Tribe, R. (2011). WPA guidance on mental health and mental health care in migrants. World Psychiatry, 10(1), 2-10. https://doi.org/10.1002/j.2051-5545.2011. tboooo2.x

Brayman, L. (2017, July 5). Is it still a Muslim ban if Christian refugees are punished? Foreign Policy. https://foreignpolicy.com/2017/07/05/is-it-stilla-muslim-ban-if-christian-refugees-are-punished-iraqi-chaldean-christianstrump/

Carlson, B. E., Cacciatore, J., \& Klimek, B. (2012). A risk and resilience perspective on unaccompanied refugee minors. Social Work, 57(3), 259-269. https://doi. org/10.1093/sw/swso03

Cooper, H., \& Shear, M. D. (2014, August 13). Militants' siege on mountain in Iraq is over, Pentagon says. The New York Times. https://www.nytimes. com/2014/08/14/world/middleeast/iraq-yazidi-refugees.html? $\mathrm{r}=0$

Darychuk, A., \& Jackson, S. (2015). Understanding community resilience through the accounts of women living in West Bank Refugee Camps. Affilia, 3o(4), 44746o. https://doi.org/10.1177/0886109915572845 
De Vido, S. (2018). Protecting Yazidi cultural heritage through women: An international feminist law analysis. Journal of Cultural Heritage, 33, 264-270. https://doi.org/10.1016/j.culher.2018.02.008

Doucet, L. (2018, September 5). Iraq Yazidis: The "forgotten" people of an unforgettable story. BBC News. https://www.bbc.com/news/ world-middle-east-45406232

Dubus, N. (2010). "I feel like her daughter not her mother": Ethnographic transcultural perspective of the experiences of aging for a group of Southeast Asian refugees in the United States. Journal of Aging Studies, 24(3), 204-211. https:// doi.org/10.1016/j.jaging.2010.02.002

Eisenbruch, M. (1991). From post-traumatic stress disorder to cultural bereavement: Diagnosis of Southeast Asian refugees. Social Science \& Medicine, 33(6), 673-68o. https://doi.org/10.1016/0277-9536(91)90021-4

Eisenbruch, M. (1997). The cry for the lost placenta: Cultural bereavement and cultural survival among Cambodians who resettled, were repatriated, or stayed at home. In M. van Tilburg \& A. Vingerhoets (Eds.), Psychological aspects of geographical moves: Homesickness and acculturation stress (pp. 105-125). Amsterdam University Press.

Eller, K. F. (2019). The trail of courage: A mini-ethnographic case study exploring the feasibility and acceptability of integrated equine-assisted Therapy (IEAT) on Yazidi adolescent girl wellbeing [Master's thesis]. https://digitalcommons.unl. edu/cehsdiss/331/

Gerdau, I., Kizilhan, J. I., \& Noll-Hussong, M. (2017). Posttraumatic stress disorder and related disorders among female Yazidi refugees following Islamic State of Iraq and Syria attacks-A case series and mini-review. Frontiers in Psychiatry, 8, Article 282. https://doi.org/10.3389/fpsyt.2017.00282

Gomez, S., \& Castaneda, H. (2019). "Recognize our humanity": Immigrant youth voices on health care in Arizona's restrictive political environment. Qualitative Health Research, 29(4), 498-509. https://doi.org/10.1177/1049732318755580

Grossman, E. S., Hoffman, Y. S., Shrira, A., Kedar, M., Ben-Ezra, M., Dinnayi, M., \& Zivotofsky, A. Z. (2019). Preliminary evidence linking complex-PTSD to insomnia in a sample of Yazidi genocide survivors. Psychiatry Research, 271, 161-166. https://doi.org/10.1016/j.psychres.2018.11.044

Hafiz, Y. (2014, August 14). Yazidi religious beliefs: History, facts and traditions of Iraq's persecuted minority. The Huffington Post. https://www.huffpost.com/ entry/yazidi-religious-beliefs_n_5671903

Hanish, S. (2009). Christians, Yazidis, and Mandaeans in Iraq: A survival issue. Digest of Middle East Studies, 18(1), 1-16.

Harrell-Bond, B. E., \& Voutira, E. (1992). Anthropology and the study of refugees. Anthropology Today, 8(4), 6-10. https://doi.org/10.2307/2783530

Hendrickson, Z. M., Kim, J., Tol, W. A., Shrestha, A., Kafle, H. M., Luitel, N. P., Thapa, L., \& Surkan, P. J. (2018). Resilience among Nepali widows after the death of a spouse: "That was my past and now I have to see my present". Qualitative Health Research, 28(3), 466-478. https://doi. org/10.1177/1049732317739265 
Hynie, M. (2018). The social determinants of refugee mental health in the postmigration context: A critical review. The Canadian Journal of Psychiatry, 63(5), 297-303. https://doi.org/10.1177/0706743717746666

Isakhan, B., \& Shahab, S. (2020). The Islamic State's destruction of Yezidi heritage: Responses, resilience and reconstruction after genocide. Journal of Social Archaeology, 2o(1), 3-25. https://doi.org/10.1177/1469605319884137

Kevers, R., Rober, P., Rousseau, C., \& De Haene, L. (2017). Silencing or silent transmission? An exploratory study on trauma communication in Kurdish refugee families. Kurdish Studies, 5(2), 3-29. https://doi.org/10.33182/ ks.v512.440

Kinnvall, C. (2004). Globalization and religious nationalism: Self, identity, and the search for ontological security. Political Psychology, 25(5), 741-767. https:// doi.org/10.1111/j.1467-9221.2004.00396

Kirmayer, L. J., Guzder, J., \& Rousseau, C. (Eds.). (2014a). Cultural consultation: Encountering the other in mental health care. Springer.

Kirmayer, L. J., Rousseau, C., \& Guzder, J. (2014b). Introduction: The place of culture in mental health services. In L. J. Kirmayer, J. Guzder, \& C. Rousseau (Eds.), Cultural consultation: Encountering the other in mental health care (pp. 1-20). Springer. https://doi.org/10.1007/978-1-4614-7615-3_10

Kizilhan, J. I. (2017). The Yazidi-Religion, culture and trauma. Advances in Anthropology, 7(4), 333-339. https://doi.org/10.4236/aa.2017.74019

Kizilhan, J. I., \& Noll-Hussong, M. (2017). Individual, collective, and transgenerational traumatization in the Yazidi. BMC Medicine, 15(1), Article 198. https://doi.org/10.1186/s12916-017-0965-7

Kizilhan, J. I., Steger, F., \& Noll-Hussong, M. (2020). Shame, dissociative seizures and their correlation among traumatised female Yazidi with experience of sexual violence. The British Journal of Psychiatry, 216(3), 138-143. https://doi. org/10.1192/bjp.2020.2

Kurt, M. (2016). In search of the holy light: Survival and resistance among Yazidi people after the ISIS Invasion of Mosul Area. Human Rights Law Review, 3. https://www.qmul.ac.uk/law/humanrights/media/humanrights/news/ hrlr/2016/In-the-Search-for-Light-Mehmet-Kurt.pdf

Langellier, K. M. (1989). Personal narratives: Perspectives on theory and research. Text and Performance Quarterly, 9(4), 243-276. https://doi. org/10.1080/10462938909365938

Langellier, K. M. (2001). Personal narrative. In M. Jolly (Ed.), Encyclopedia of life writing: Autobiographical and biographical forms (Vol. 2, pp. 699-701). Fitzroy Dearborn.

Lenette, C., Brough, M., \& Cox, L. (2013). Everyday resilience: Narratives of single refugee women with children. Qualitative Social Work, 12(5), 637-653. https:// doi.org/10.1177/1473325012449684

Lewis, D. C. (2008). Types, meanings and ambivalence in intergenerational exchanges among Cambodian refugee families in the United States. Ageing and Society, 28(5), 693-715. https://doi.org/10.1017/S0144686X08007034 
Ludwig, P. (2008). Kurdish language: History of the Kurdish language. Encyclopaedia Iranica (Online ed.). https://iranicaonline.org/articles/ kurdish-language-i

McMichael, C., \& Manderson, L. (2004). Somali women and well-being: Social networks and social capital among immigrant women in Australia. Human Organization, 63(1), 88-99. www.jstor.org/stable/44126994

McMorrow, S., \& Saksena, J. (2017). Voices and views of Congolese refugee women: A qualitative exploration to inform health promotion and reduce inequities. Health Education \& Behavior, 44(5), 769-780. https://doi. org/10.1177/1090198117726572

Nasıroğlu, S., \& Ceri, V. (2016). Posttraumatic stress and depression in Yazidi refugees. Neuropsychiatric Disease and Treatment, 12, 2941-2948. https://doi. org/10.2147/NDT.S119506

Nichter, M. (1981). Idioms of distress: Alternatives in the expression of psychosocial distress: A case study from South India. Culture, Medicine and Psychiatry, 5(4), 379- 408. https://doi.org/10.1007/BFoo054782

Nichter, M. (2010). Idioms of distress revisited. Culture, Medicine and Psychiatry, 34(2), 401-416. https://doi.org/10.1007/s11013-010-9179-6

Omata, N. (2013). Repatriation and integration of Liberian refugees from Ghana: The importance of personal networks in the country of origin. Journal of Refugee Studies, 26(2), 265-282. https://doi.org/10.1093/jrs/feso23

Panter-Brick, C., \& Eggerman, M. (2012). Understanding culture, resilience, and mental health: The production of hope. In M. Ungar (Ed.), The social ecology of resilience (pp. 369-386). Springer.

Pearce, E., McMurray, K., Walsh, C. A., \& Malek, L. (2017). Searching for tomorrow-South Sudanese women reconstructing resilience through photovoice. Journal of International Migration and Integration, 18(2), 369-389. https://doi.org/10.1007/s12134-016-0500-2

Pike, I. L. (2019). Intersections of insecurity, nurturing, and resilience: A case study of Turkana women of Kenya. American Anthropologist, 121(1), 126-137. https://doi.org/10.1111/aman.13153

Posselt, M., Eaton, H., Ferguson, M., Keegan, D., \& Procter, N. (2019). Enablers of psychological well-being for refugees and asylum seekers living in transitional countries: A systematic review. Health \& Social Care in the Community, 27(4), 8o8-823. https://doi.org/10.1111/hsc.12680

Pulvirenti, M., \& Mason, G. (2011). Resilience and survival: Refugee women and violence. Current Issues in Criminal Justice, 23(1), 37-52. https://doi.org/10.10 $\underline{80 / 10345329.2011 .12035908}$

Raasch, C. (2019). The crisis of crisis response: The cultural consequences of global mental health interventions. Reconsidering Development, 6(1). https:// pubs.lib.umn.edu/index.php/reconsidering/article/view/1362

Rai, M., \& Paul, S. (2020). Human rights of women refugees. In W. Leal Filho, A. Azul, L. Brandli, A. Lange Salvia, \& T. Wall (Eds.), Gender equality, encyclopedia of the UN sustainable development goals. Springer. https://doi. org/10.1007/978-3-319-70060-1 74-1 
Said, R., \& Reuters. (2014, August 11). File photo: Displaced people from the minority Yazidi sect, fleeing violence from forces loyal to the Islamic State in Sinjar town, walk towards the Syrian border on the outskirts of Sinjar mountain near the Syrian border town of Elierbeh of Al-Hasakah Governorate in this August 11, 2014. https://www.theatlantic.com/international/archive/2014/08/ the-yazidis-a-people-who-fled/375964/

Saksena, J., \& McMorrow, S. L. (2020). Through their eyes: A photovoice and interview exploration of integration experiences of Congolese refugee women in Indianapolis. Journal of International Migration and Integration, 21, 529-549. https://doi.org/10.1007\%2Fs12134-019-00672-1

Shishehgar, S., Gholizadeh, L., DiGiacomo, M., Green, A., \& Davidson, P. M. (2017). Health and socio-cultural experiences of refugee women: An integrative review. Journal of Immigrant and Minority Health, 19(4), 959-973. https://doi. org/10.1007/s10903-016-0379-1

Siriwardhana, C., Ali, S. S., Roberts, B., \& Stewart, R. (2014). A systematic review of resilience and mental health outcomes of conflict-driven adult forced migrants. Conflict and Health, 8(1), 13. https://doi.org/10.1186/1752-1505-8-13

Strang, A., \& Ager, A. (2010). Refugee integration: Emerging trends and remaining agendas. Journal of Refugee Studies, 23(4), 589-607. https://doi.org/10.1093/ jrs/feq046

Szaflarski, M., \& Bauldry, S. (2019). The effects of perceived discrimination on immigrant and refugee physical and mental health. Immigration and Health, 19, 173-204.

Tagay, S., Ayhan, D., Catani, C., Schnyder, U., \& Teufel, M. (2017). The 2014 Yazidi genocide and its effect on Yazidi diaspora. The Lancet, 390(10106), 1946. https://doi.org/10.1016/S0140-6736(17)32701-0

Theron, L. C., \& Liebenberg, L. (2015). Understanding cultural contexts and their relationship to resilience processes. In L. C. Theron, L. Liebenberg, \& M. Ungar (Eds.), Youth resilience and culture (pp. 23-36). Springer.

Thomas, F. C., Roberts, B., Luitel, N. P., Upadhaya, N., \& Tol, W. A. (2011). Resilience of refugees displaced in the developing world: A qualitative analysis of strengths and struggles of urban refugees in Nepal. Conflict and Health, 5(1), 20. https://doi.org/10.1186/1752-1505-5-20

Tippens, J. A. (2017). Urban Congolese refugees in Kenya: The contingencies of coping and resilience in a context marked by structural vulnerability. Qualitative Health Research, 27(7), 1090-1103. https://doi. org/10.1177/1049732316665348

Tippens, J. A. (2020). Urban Congolese refugees' social capital and community resilience during a period of political violence in Kenya: A qualitative study. Journal of Immigrant \& Refugee Studies, 18(1), 42-59. https://doi.org/10.1080/ 15562948.2019 .1569744

Turrini, G., Purgato, M., Ballette, F., Nose, M., Ostuzzi, G., \& Barbui, C. (2017). Common mental disorders in asylum seekers and refugees: Umbrella review of prevalence and intervention studies. International Journal of Mental Health Systems, 11(1), 51. https://doi.org/10.1186/s13033-017-0156-0 
Ungar, M. (2011). The social ecology of resilience: Addressing contextual and cultural ambiguity of a nascent construct. American Journal of Orthopsychiatry, 81(1), 1-17. https://doi.org/10.1111\%2Fj.1939-0025.2010.01067.X

U.S. Office of Refugee Resettlement. (2020, July 7). Emotional wellness. https:// www.acf.hhs.gov/orr/emotional-wellness-o

VERBI Software. (2019). MAXQDA 2020 [computer software]. Berlin, Germany: VERBI Software. Available from maxqda.com.

Wachter, K., Dalpe, J., Bonz, A., Drozdowski, H., \& Hermer, J. (2020). A scoping review of social support interventions with refugees in resettlement contexts: Implications for practice and applied research. Journal of Immigrant \& Refugee Studies. https://doi.org/10.1080/15562948.2020.1854917

Wang, C. C. (1999). Photovoice: A participatory action research strategy applied to women's health. Journal of Women's Health, 8(2), 185-192. https://doi. org/10.1089/jwh.1999.8.185

Wang, C. C., \& Burris, M. A. (1997). Photovoice: Concept, methodology, and use for participatory needs assessment. Health Education and Behavior, 24(3), 369-387. https://doi.org/10.1177/109019819702400309

Wexler, L., DiFluvio, G., \& Burke, T. (2009). Resilience in response to discrimination and hardship: Considering the intersection of personal and collective meaning-making for Indigenous and GLBT youth. Social Science \& Medicine, 69, 565-570. https://doi.org/10.1016/j.socscimed.2009.06.022

Yazda. (2020). Yazda: Global Yazidi organization. https://www.yazda.org

Yezidis International. (n.d.). Yezidi holidays and festivals. http://www. yezidisinternational.org/abouttheyezidipeople/holidays/

Yotebieng, K. A., Syvertsen, J. L., \& Awah, P. (2019). "Is wellbeing possible when you are out of place?” Ethnographic insight into resilience among urban refugees in Yaounde, Cameroon. Journal of Refugee Studies, 32(2), 197-215. https://doi.org/10.1093/jrs/feyo23

Ziersch, A., Due, C., \& Walsh, M. (2020). Discrimination: A health hazard for people from refugee and asylum-seeking backgrounds resettled in Australia. BMC Public Health, 20(1), Article 108. https://doi.org/10.1186/ s12889-019-8068-3

$\diamond \diamond \diamond \diamond \diamond$

\section{Author Biographies}

Julie A. Tippens is an Assistant Professor of Child, Youth and Family Studies at the University of Nebraska-Lincoln. Her research focuses on refugees' health and resilience.

Kaitlin Roselius is a doctoral student in Child, Youth and Family Studies at the University of Nebraska-Lincoln. Her research focuses on community-based prevention strategies. 
Irene Padasas is a doctoral candidate in Child, Youth and Family Studies at the University of Nebraska-Lincoln. Her research centers on understanding issues surrounding families in tenuous caregiving conditions and rapidly shifting contexts.

Gulie Khalaf co-founded Yezidis International, an organization dedicated to preserving the Yezidi culture and faith, educating the public about Yezidis, and empowering Yezidis in Lincoln, Nebraska and worldwide.

Kara Kohel is an Assistant Extension Educator with Nebraska Extension. Her work supports adult caregivers of young children.

Elizabeth Mollard is an Assistant Professor in the College of Nursing at the University of Nebraska Medical Center.

Izdihar (Vianne) Sheikh coordinates the Untold Migrant Stories Program at the Asian Community and Cultural Center of Lincoln, Nebraska and is in the BFA program in Emerging Media Arts at the University of Nebraska-Lincoln. 